\title{
Awareness, Knowledge and Comprehension of Media Messages on Family Planning as Predictors of Practice among Civil Servants in Lagos State, Nigeria
}

\author{
Helen Odunola Adekoya ${ }^{1}$, Mofoluke Akoja ${ }^{1}$, Charles Maduabuchi Ekeh ${ }^{1} \&$ Nneoma Anaeto ${ }^{1}$ \\ ${ }^{1}$ Babcock University, Ilishan-Remo, Ogun State, Nigeria \\ Correspondence: Helen Odunola Adekoya, Babcock University, Ilishan-Remo, Ogun State, Nigeria.
}

Received: September 2, 2019 Accepted: December 11, 2019 Online Published: December 29, 2019

doi:10.5539/gjhs.v12n1p96 URL: https://doi.org/10.5539/gjhs.v12n1p96

\begin{abstract}
Family planning is a population control method practiced in various countries including Nigeria; however, it cannot be practice unless people are aware of it and its methods. Thus, awareness, knowledge and comprehension of family planning messages as predictors of practice is studied. 478 copies of questionnaire were distributed to that number of civil servants at the Lagos state secretariat, Alausa from where the population for the study was drawn. With a response rate of $95.8 \%, 458$ copies were retrieved and analyzed using the statistical package for social sciences (SPSS) version 22, while hypotheses were tested using the Pearson Chi-Square. Findings revealed that there is high awareness of family planning messages among study participants with posters as the major medium of awareness. The study also found that the long-acting family planning methods are the most known family planning methods and that the practice is well known and common among study participants.
\end{abstract}

Keywords: awareness, knowledge, family planning messages, family planning practice

\section{Introduction}

Family planning is about helping individuals or couples determine the number of children they wish to or not to have. The concept has been around for centuries with different generations across different regions of the world adopting various ways of controlling childbirth and increasing child spacing in order to enable couples give birth to the number of children they can adequately care for. Family planning is considered to be a safer and better approach of child spacing and child bearing when compared to abortion because it adopts a proactive process in helping highly fertile couples and individuals to regulate their fertility and produce the number of children they want in such manner as to prevent maternal mortality and morbidity. Its wide acceptability have led to its promotion through the formulation of policies in different countries across Asia, Europe and America where family planning is seen as not only a method of regulating birth and family size but also a method through which population explosion can be checked. While China adopted the one child per-couple policy in 1979 and repealed it in 2015, others have practiced such natural methods as abstinence, withdrawal and safe period, with many others choosing various orthodox medical approaches.

However, the story is quite different among countries in the African region. Studies have shown that most of the countries with lowest rates of contraceptive use, highest maternal, infant, and child mortality rates, and highest fertility rates are in Africa (World Bank, 2015, 2016, 2017). Also, Cleland, Peipert, Westhoff, Spear and Trussell (2011) found that only about $30 \%$ of all women in the region use birth control due to paucity of information and non-availability of resources. The World Health Organisation (WHO, 2018) observed that main problems preventing access to and use of birth control among women in Africa are unavailability, poor health care services, spousal disapproval, inadequate information, religious concerns, and misinformation about the effects of birth control.

In the case of Nigeria, regarded as the most populous country in Africa, with population figures around 190.9 million (World Bank, 2017), the situation is not different from what obtains in other countries in Africa. Despite that the concept of family planning has been known in the country since the 1950s (Bridget \& Erua, 2016), when it was first promoted by the Federation Women Council of Nigeria through the inauguration of the Planned Parenthood of Nigeria (PPN), its adoption and practice among women in the country has been scanty. Since then, concerns about high fertility and low contraceptive prevalence in sub-sub-Saharan Africa more especially Nigeria 
have stimulated policy and programme efforts aimed at promoting family planning in the region (Akinrinola, 1994). Excluding other population control methods such as disease, war, or other natural and manmade disasters, family planning is a population control method that must be practiced in a country ridden by overpopulation. In the quest to control population growth, the government of Nigeria in 2002 came out with a population policy paper on family planning and fertility regulation which noted that (Osakue, 2010):

the value of family planning and child spacing on the stability and wellbeing of family shall be promoted and family services shall be incorporated in maternal and child health care. This is to help reduce maternal and infant morbidity and mortality as well as reduce rapid population growth in the shortest possible time in order to ensure sustainable development which can be achieved only by reducing population growth to bring it to per with the available national resources. This will invariably lead to the attainment of good quality life and high standard of living in the country (p. 78).

Family planning provides the society with some socio-economic and health benefits (Odaman, 2005). Awareness of such benefits can significantly enhance the use of contraceptives, which in turn, will reduce population growth and overtime have positive effects on national development. Ugoji (2008) observes that family planning programmes prevent unwanted pregnancies, help achieve birth spacing and help couples limit family size so as to reduce maternal/infant mortality as well as poverty. Further, Osakue (2010) stated that the health benefits of family planning associated with child spacing and the use of specific methods can play a major role in protecting the lives of infants, children, women and the family as a whole on the continent of Africa. In order to ensure informed choice of family planning and reproductive health behaviour in regards to the modern methods of family planning, Oladeji (2008) contends that communication and decision making play a vital role. Recent research based on nationality representative surveys confirms a strong association between exposure to family messages in the mass media and contraceptive use, even after the effects of social and demographic variables are controlled (Hasan \& Bten, 2005). Multiple exposure through the media play important role in educating couples on the benefits of small families and provide regular information on contraception and its use (Okigbo, Speizer, Meghan, \& Abdou, 2015). Therefore, substantial money and time are currently being spent for the purpose of educating people about the advantages of family planning through mass media messages ranging from campaigns on television to radio and print as well as through the online media.

Having realized the need for supportive efforts on family planning, governments around the world have begun using the mass media for disseminating family planning messages. Awareness is an indispensable step to behaviour change. If people are expected to use contraceptives, they have to be aware of the different options available and where they are obtainable. It is therefore necessary that while providing information on the types of family planning methods, information should also be given on the types of establishments which provide family planning services. General practice in a number of developing countries has shown that one of the key factors in this process has been the implementation of multimedia health communication campaigns that are aimed at promoting family planning and raising awareness regarding the availability of pertinent health services. Previous research like that of Bongaarts, Cleland, John, Townsend, Bertrand, and Gupta (2012) highlighted a positive relationship between multimedia health communication campaigns and increase in people's use of health services and advanced medical technologies, as well as the impact of these campaigns on combating various pandemics and unhealthy practices. Similarly, Piotrow, Rimon II, Winnard, Kincaid, Huntington, and Conviser (1990) noted that mass media can be a powerful tool not only for creating awareness about new technology but also for stimulating people's desires for more information and facilitating their efforts to apply the information to their own behaviour. Parlato (1990) argued that a well-designed media campaign can be effective in creating a positive social environment for behaviour by bringing about a shift in popular opinion. The proponents of this approach have argued that the increasing availability of family planning messages using the mass media in developing countries can be effectively used to influence people's behaviour towards family planning.

Evidences abound that exposure to information on mass media has effects on changing people's attitude or behavior towards contraceptive use (Westoff \& Rodriguez, 1995; Gupta, Katende, \& Bessinger, 2004). Exposure to mass media makes firsthand information about contraceptive methods possible thereby making couples have adequate knowledge about various contraceptives methods, their benefits, side effects and correct the wrong perception about family planning among the populace. With this knowledge, couples can be encouraged to choose the practice of family planning. Nigeria, like other developing and densely populated countries, has family planning as one of its Sustainable Development Goals (SDGs) and its government and non-governmental organisations employ the mass media to both inform and motivate people about this complex subject with the hope of causing a change in their behaviour towards it. Being that family planning and population control is one of the Sustainable Development Goals (SDGs) set by the United Nations in 2015 in order to control population figures, 
Nigeria is yet to achieve this goal.

Previous studies have demonstrated the effectiveness of the mass media on the awareness, knowledge and practice of family planning; however, none has evaluated the awareness, knowledge and comprehension of these messages as predictors of family planning practice based on media messages delivered through traditional television and online platforms in the format of an education-entertainment series on family planning as well as through posters simultaneously. This study attempts to fill this gap by evaluating audience' awareness, knowledge and comprehension of messages using the edutainment media series "Newman Street", which was delivered to the audience through television and YouTube channels and the Nigerian Urban Reproductive Health Initiative (NURHI) "modern family planning/childbirth spacing method" posters placed at strategic places such as hospitals, community health centers and public health facilities. The mass media has been used to disseminate information about brands, products, events and government policies among others with great effect on its target audience, there is therefore the need to identify, assess and evaluate its effect on the awareness and knowledge of audience, as well as the extent to which they comprehend family planning messages and practice it. Newman Street is a high profile edutainment television drama series set in the heart of a vibrant, urban slum in Nigeria and scripted to promote family planning measures as well as malaria-prevention practices. The posters used were those of modern family planning/childbirth spacing method (MFP/CSM), which is a communication initiative of the Get It Together (GIT) campaign set up by the Nigerian Urban Reproductive Health Initiative (NURHI) used in determining activities to generate massive demand for family planning with a focus on branding of the communication initiative and flagship mass media campaigns. The Agenda-Setting and Social Learning theories provide the theoretical framework for the study, while the following null hypotheses were tested at $5 \%$, level of significance using the Pearson Chi-Square.

$\mathbf{H}_{\mathbf{0}} \mathbf{1}$ : Awareness of family planning messages does not have significant influence on practice of family planning

$\mathbf{H}_{\mathbf{0}}$ 2: Knowledge of family planning methods does not have significant influence on practice of family planning

$\mathbf{H}_{\mathbf{0}}$ 3: Comprehension of family planning messages does not have significant influence on practice of family planning.

\section{Materials and Methods}

This is an explorative study using the descriptive survey research design. Survey research method, according to Wiseman and Aron (as cited in Johnson, 2012), is a method for collecting and analyzing data via highly structured and often very detailed interview or questionnaire in order to obtain information from large numbers of respondents presumed to be representatives of its specific population. The survey research method is an effective research method for this study as it enabled the researchers to sample respondents in order to gather accurate opinions and views and to produce data which are valid, reliable and useful for making generalizations. 478 copies of questionnaire were distributed to that number of civil servants at the Lagos state secretariat, Alausa from where the population for the study was drawn. With a response rate of $95.8 \%, 458$ copies were retrieved and analyzed using the statistical package and service solutions (SPSS) version 22, while hypotheses were tested using the Pearson Chi-Square.

\section{Data Analysis, Results and Discussion of Findings}

\subsection{Testing of Hypothesis}

$\mathbf{H}_{\mathbf{0}} \mathbf{1}$ : Awareness of family planning messages does not have significant influence on practice of family planning.

Table 1a. Influence of awareness of family planning messages on practice of family planning

\begin{tabular}{lccccc}
\hline \multicolumn{5}{c}{ Chi-Square Tests } \\
\hline & Value & Df & Asymp. Sig. (2-sided) & Exact Sig. (2-sided) & Exact Sig. (1-sided) \\
\hline Pearson Chi-Square & $2.821^{\mathrm{a}}$ & 1 & .037 & & \\
Continuity Correction & 1.299 & 1 & .018 & .043 & .014 \\
Likelihood Ratio & 3.311 & 1 & .011 & \\
Fisher's Exact Test & & & & \\
Linear-by-Linear Association & 1.231 & 1 & .021 & \\
N of Valid Cases & 458 & & & & \\
\hline
\end{tabular}

The Pearson Chi-Square row in Table 1 predicts that since the p-value $3.7 \%$ is less than the alpha value 5\%, this means the result is statistically significant and then the alternative hypothesis which states that 'awareness of 
family planning messages has significant influence on practice of family planning' should be accepted and the null hypothesis should be rejected.

Table $1 \mathrm{~b}$. Symmetric measures on the size of effect of awareness of family planning messages on practice on family planning

\begin{tabular}{llcc}
\hline \multicolumn{3}{c}{ Symmetric Measures } \\
\hline & Value & Approx. Sig. \\
\hline Nominal by Nominal & Phi & .841 & .019 \\
N of Valid Cases & .841 & .019 \\
\hline a. Not assuming the null hypothesis. & 458 & \\
b. Using the asymptotic standard error assuming the null hypothesis. & \\
\hline
\end{tabular}

The value column in Table $1 \mathrm{~b}$ above states the effect or size of effect which awareness of family planning messages have on practice of family planning; this value thus shows an $84.1 \%$ effect on the practice of family planning. This can further be explained by stating that awareness of family planning messages has an $84.1 \%$ influence on the practice of family planning generally.

$\mathbf{H}_{\mathbf{0}} \mathbf{1}$ : Knowledge of family planning methods does not have significant influence on practice of family planning.

Table 2a. Influence of knowledge of family planning methods on practice of family planning

\begin{tabular}{lccccc}
\hline \multicolumn{7}{c}{ Chi-Square Tests } \\
\hline & Value & Df & Asymp. Sig. (2-sided) & Exact Sig. (2-sided) & Exact Sig. (1-sided) \\
\hline Pearson Chi-Square & $4.851^{\mathrm{a}}$ & 1 & .028 & & \\
Continuity Correction ${ }^{\mathrm{b}}$ & 5.771 & 1 & .028 & .012 & .032 \\
Likelihood Ratio & 2.531 & 1 & .029 & & \\
Fisher's Exact Test & & & & & \\
Linear-by-Linear Association & 9.522 & 1 & 031 & & \\
N of Valid Cases & 458.0 & & & & \\
\hline
\end{tabular}

Table 2a shows the Pearson Chi- square test which gave a result of the p-value of $2.8 \%$ which is less than the alpha value 5\%, this means that the result is significant and thus makes the alternative hypothesis which states that 'knowledge of family planning methods has significant influence on practice of family planning' should be accepted and the null hypothesis be rejected.

Table 2b. Symmetric measures on the size of effect of knowledge of family planning methods on practice on family planning

\begin{tabular}{lccc}
\hline \multicolumn{4}{c}{ Symmetric Measures } \\
\hline \multirow{3}{*}{ Nominal by Nominal } & Phi & Value & Approx. Sig. \\
& Cramer's V & .683 & .012 \\
N of Valid Cases & .683 & .012 \\
\hline a. Not assuming the null hypothesis. & 458.0 & \\
b. Using the asymptotic standard error assuming the null hypothesis. \\
\hline
\end{tabular}

Table $2 b$ shows the symmetric measure of the hypothesis test, it gives the value of impact which the accepted hypothesis has on the research study. The column titled 'value' gives the figure 0.683 which is interpreted as $68.3 \%$, it means that knowledge of family planning methods has an above average impact on the practice of family planning.

$\mathbf{H}_{\mathbf{0}} \mathbf{1}$ : Comprehension of family planning messages does not have significant influence on practice of family planning. 
Table 3a. Influence of comprehension of family planning messages on practice of family planning

\begin{tabular}{lccccc}
\hline \multicolumn{5}{c}{ Chi-Square Tests } \\
\hline & Value & Df & Asymp. Sig. (2-sided) & Exact Sig. (2-sided) & Exact Sig. (1-sided) \\
\hline Pearson Chi-Square & $3.431^{\mathrm{a}}$ & 1 & .019 & & \\
Continuity Correction ${ }^{\mathrm{b}}$ & 3.233 & 1 & .013 &. & .012 \\
Likelihood Ratio & 4.322 & 1 & .018 & .022 \\
Fisher's Exact Test & & & & \\
Linear-by-Linear Association & 13.320 & 1 & .024 & & \\
N of Valid Cases & 458 & & & & \\
\hline
\end{tabular}

The Pearson Chi-Square row in Table 3a predicts that since the p-value $1.9 \%$ is less than the alpha value 5\%, this means the result is statistically significant and then the alternative hypothesis which states that "comprehension of family planning messages has significant influence on practice of family planning' should be accepted and the null hypothesis should be rejected.

Table 3b. Symmetric measures on the size of effect of comprehension of family planning messages on practice on family planning

\begin{tabular}{llcc}
\hline \multicolumn{3}{c}{ Symmetric Measures } \\
\hline
\end{tabular}

The value column in Table $3 b$ shows the effect or size of effect of comprehension of family planning messages to the practice of family planning; this value thus show that the comprehension of family planning messages has a $71.1 \%$ effect on the practice of family planning. Therefore, the comprehension of family planning messages has a high effect on the practice of family planning.

\section{Discussion of Findings}

A significant majority of the respondents are aware of family planning messages (95.7\%) mostly on a regular basis and the major medium through which they are made aware about family planning is posters (such as the modern family planning/childbirth spacing method (MFP/CSM) posters) (26.2\%). Other major media include enlightenment and education from hospitals, television programmes and information from family and friends. This finding is contrary to the findings of Rajesh, Premarajan, Narayan and Akshaya (2003) which found that magazine is the main source of information on family planning as well as the findings of Omolase, Faturoti and Omolase (2009) and Obalase and Joseph (2017) which state that the major means of information on family planning is hospitals and/or health workers and the findings of Sharma, Dorairajan, and Chinnakali (2015) which showed that the most frequent source of information was social circle and friends.

Similar to how Kigaru, Krenn, Kusemiju, Ajioye, Chidi, and Kalu (1996) found that the Public Service Announcement (PSA) campaign and the Logo campaign they researched on reached a large proportion of the intended audience with messages that were understandable and easily recalled, focusing on the television series known as Newman Street, the researchers found that most of the respondents were aware of the series (86.9\%), thus the series plays a role in the dissemination of family planning messages. However, with the significance of the family planning messages disseminated through Newman Street and the fact that $22.1 \%$ of the respondents are unaware of the series, it is recommended that the agencies responsible for the programme, such as Centre for Communication Programmes Nigeria (CCPN) and Nollywood Concept Promotions (NCP), should further promote the series and air it on more channels and, where possible, have a channel dedicated to airing only the series as it is with Big Brother Nigeria. Although Sharma et al. (2015) found that the level of awareness about spacing contraception was very high, this study found that on average, the awareness of media messages on family planning is high, with poster messages being more effective than television programmes.

In relation to knowledge of family planning methods based media messages, findings showed that over $70 \%$ of the 
respondents understand that family planning is meant for male and female and that family planning is safe. Also, the most known family planning methods to the respondents based on media messages they come across were the long-acting family planning methods (such as using Implants and Intrauterine Contraceptive Devices (IUDs or IUCDs) (85.3\%), followed by short-acting family planning methods (such as oral contraceptives pills, injectables, condoms and exclusive breastfeeding method (LAM)) (78\%), and lastly permanent family planning methods (such as tubal litigation and vasectomy) (76.9\%). This finding contradicts the findings of Otieno (1999) which showed that the most widely known methods were the condom, the pill, female sterilization, and periodic abstinence as well as the findings of Omolase et al., which showed that the most known family planning method was condom. Agreeing with Otieno (1999) who found that there is high level of knowledge of family planning methods and source and favourable attitude among men in Kenya, this study found that the knowledge of family planning methods based on media messages is high.

In agreement with Hovland and Weiss (as cited in Anaeto, Onabanjo \& Osifeso, 2008) who stated that the dimensions of source credibility include expertness and trustworthiness, the findings of this study revealed that most, $(82.7 \%)$, of the respondents trust the messages gotten about family planning. The researchers also found out that respondents understand the language type used in family planning media messages which shows in the understanding of the content of posters on family planning messages and the understanding of the different methods of family planning and how they can be administered. In further support of the finding that television programmes are effective in publicizing family planning messages Osakue (2016) found that radio and television, through certain programmes, have helped in the dissemination of relevant information on family planning in rural settings just as they have purportedly done in urban centres in Nigeria, this study also found that the achievability of the family planning methods portrayed in the television series, Newman Street, is low (72.9\%, MIB=2.47). However, on average, the level of comprehension of family planning messages by the audience is high.

The researchers found that to a very high level, media messages encouraged the use of family planning just as Odewale, Oladosun and Amoo (2016) found that exposure to family planning information via various media are significantly related to contraceptive use in Nigeria. This is in relation with the other findings made in this study which show that getting more understanding of family planning messages and methods will encourage practice (87.1) and that the understanding of family planning messages and methods influenced their use of family planning methods (79.9\%). Therefore, on average, the practice of family planning among respondents is high.

\section{Conclusion}

Family planning practice in Nigeria and other countries in Africa is said to be low despite the availability of information about it. However, findings from this study have demonstrated that awareness and practice of family planning is improving due to various media campaigns promoting it among couples and individuals. Among the categories of media studied - television drama and family planning posters, respondents in this study indicated that their major medium of awareness were the posters while a section who were exposed to other media also enjoyed the enlightenment and education from hospitals, television programmes and information from family and friends. This shows that between the television series known as the Newman Street and the Modern Family Planning/Childbirth Spacing Method (MFP/CSM) posters, the preferred medium of receiving family planning messages is the MFP/CSM posters. This is understandable since the posters were handier and could be read easily. This study concludes that awareness, knowledge and comprehension of media messages on family planning can predict the rate at which the audience practice family planning. It is therefore recommended that government, non-governmental agencies, medical institutions and other agencies can take advantage of the platform which the media provides to disseminate important information that will make the audience aware and enhance their knowledge about family planning in order to encourage them to practice it.

\section{References}

Akinrinola, B. (1994). The role of mass media in family planning in Nigeria. Demographic and Health Surveys, (11).

Anaeto, S. G., Onabanjo, O. S., \& Osifeso, J. B. (2008). Models and theories of communication. Nigeria, Lagos: African Renaissance Books Incorporated.

Bongaarts, J., Cleland, J., John, W., Townsend, J., Bertrand, T., \& Gupta, D. (2012). Family planning programs for the 21st century: Rationale and design. Population Council: New York, NY. Marriage a scoping study for girls not brides: The global partnership to end child marriage. Center for Media \& Health - dance4life.

Bridget, E. U., \& Erua, C. H. (2016). Family planning awareness and usage among women: Implication for family 
life education. British Journal of Education, Society \& Behavioural Science, 16(2), 1-7. https://doi.org/10.9734/BJESBS/2016/25776

Cleland, K., Peipert, J. F., Westhoff, C., Spear, S., \& Trussell, J. (May 2011). Family planning as a cost-saving preventive health service. New England Journal of Medicine, 364(18), e37. https://doi.org/10.1056/NEJMp1104373

Hasan, S., \& Baten, A. (2005). Role of mass media in promoting family planning in Bangladesh. Journal of Applied Sciences, 5(7), 1158-1162. https://doi.org/10.3923/jas.2005.1158.1162

Kigaru, K., Krenn, S., Kusemiju, B., Ajioye, J. K. T., Chidi, I., \& Kalu, O. (1996). Promoting family planning through mass media in Nigeria: Campaigns using a public service announcement and a national logo. Baltimore, Maryland: Johns Hopkins Center for Communication Programs.

Newman street tv series. (2018). Retrieved October 15, 2018 from https://newmanstreetng,tv

Nigeria's newman street targets family planning, malaria. (2014). Retrieved October 15, 2018 from https://ccp.jhu.edu/2014/10/16/nigerias-newest-tv-series-newman-street-targets-family-planning-malaria/

Obalase, S. B., \& Joseph, U. E. (2017). Knowledge, attitude and acceptance of modern family planning method among women attending post-natal clinic in Ayeka basic health centre in Okitipupa local government area, Ondo state, Nigeria. Biomedical Journal of Scientific and Technical Research, 1(4). https://doi.org/10.26717/BJSTR.2017.01.000361

Odaman, O. M. (2005). Some socio-economic and demographic determinants of family planning practice of married women in Ekpoma, Edo State, Nigeria. Iroro: A Journal of Arts, $10(1$ and 2): 153-159.

Odewale, B. J., Oladosun, M., \& Amoo, E. O. (2016). Multiple exposure to information about family planning and contraceptive use among women in Nigeria. $3^{\text {rd }}$ International Conference on African Development Issues.

Okigbo, C. C., Speizer, I. S., Meghan C., \& Abdou, G. (2015). Exposure to family planning messages and modern contraceptive use among men in urban Kenya, Nigeria, and Senegal: A cross-sectional study. Reproductive Health, 12(63), 2015. https://doi.org/10.1186/s12978-015-0056-1

Oladeji, D. (2008). Communication and decision-making factors influencing couples' interest in family planning and reproductive health behaviors in Nigeria. Studies of Tribes and Tribal, 6(2), 99-103. https://doi.org/10.1080/0972639X.2008.11886582

Omolase, C. O., Faturoti, S. O., \& Omolase, B. O. (2009). Awareness of family planning amongst antenatal patients in a Nigerian community: An exploratory study. Annals of Ibadan Postgraduate Medicine, 7(1). https://doi.org/10.4314/aipm.v7i1.64076

Osakue, S. O. (2010). Broadcast media in family planning matters in rural Nigeria: The Ebelle scenario. $J$ Communication, 1(2), 77-85. https://doi.org/10.1080/0976691X.2010.11884773

Otieno, P. O. (1999). Men's knowledge, attitude and practice of family planning in Kenya. Demography.

Parlato, M. B. (1990). The use of mass media to promote breastfeeding. International Journal of Gynecology and Obstetrics, 31(suppl. 1), 105-110. https://doi.org/10.1016/0020-7292(90)90086-Z

Piotrow, P. T., Rimon II, G. J., Winnard, D. I., Kincaid, D. L., Huntington, D., \& Conviser, J. (1990). Mass media family planning promotion in Nigerian cities. Studies in Family Planning, 21(5), $265-274$. https://doi.org/10.2307/1966506

Population Reports. (1986). Family planning programs. Series J, No. 32, September-October 1986.

Rajesh, R. S., Premarajan, K. C. Narayan, K. A., \& Akshaya, K. M. (2003). Rapid appraisal of knowledge, attitude and practices related to family planning methods among men within 5 years of married life. Indian J. Prev. Soc. Med., 34(1\&2).

Sharma, J., Dorairajan, G., \& Chinnakali, P. (2015). Knowledge and attitude towards contraceptive methods for spacing and decision making factors regarding its use in postpartum women. International Journal of Reproduction, Contraception, Obstetrics Gynecology, $4(3)$. https://doi.org/10.18203/2320-1770.ijrcog20150086

Ugoji, F. N. (2008). Attitude of undergraduates towards contraceptive use. Pakistan Journal of Social Sciences, 5(1), 111-115.

United Nations Fund for Population Affairs. (1996). State of the world population: Reproductive health and family 
planning. Retrieved on July 18, 2018 from http://www.unfpa.org/swp/2004/english/ch6/index.htm

United Nations Population Fund. (2001). Retrieved on July 18, 2018 from http://www.unfpa.org/population-trends United Nations. (2005). World population prospects: The 2004 Revision. New York: United Nations.

Westoff, C. F., \& Rodriguez, G. (1995). The mass media and family planning in Kenya. DHS Working Papers, No. 4. https://doi.org/10.2307/2133602

World Bank, (2016). Birth rate, crude (per 1,000 people). Retrieved 12 August 2019.

World Bank. (2010). World Development Report 2010. New York, Oxford University Press and Washington DC: The World Bank.

World Bank. (2015). Maternal mortality ratio (modeled estimate, per 100,000 live births). Retrieved 12 August 2019.

World Bank. (2017a). Fertility rate, total (births per woman). Retrieved 12 August 2019.

World Bank. (2017b). World development indicators. Retrieved from http://datatopics.worldbank.org/world-development-indicators/

World Health Organization (WHO, 2018). Family planning/Contraception. Retrieved 12 August 2019.

World Health Organization. (2013). Family planning. Retrieved on July 18, 2018 from http://www.who.int/topics/family_planning/en/

\section{Appendix I}

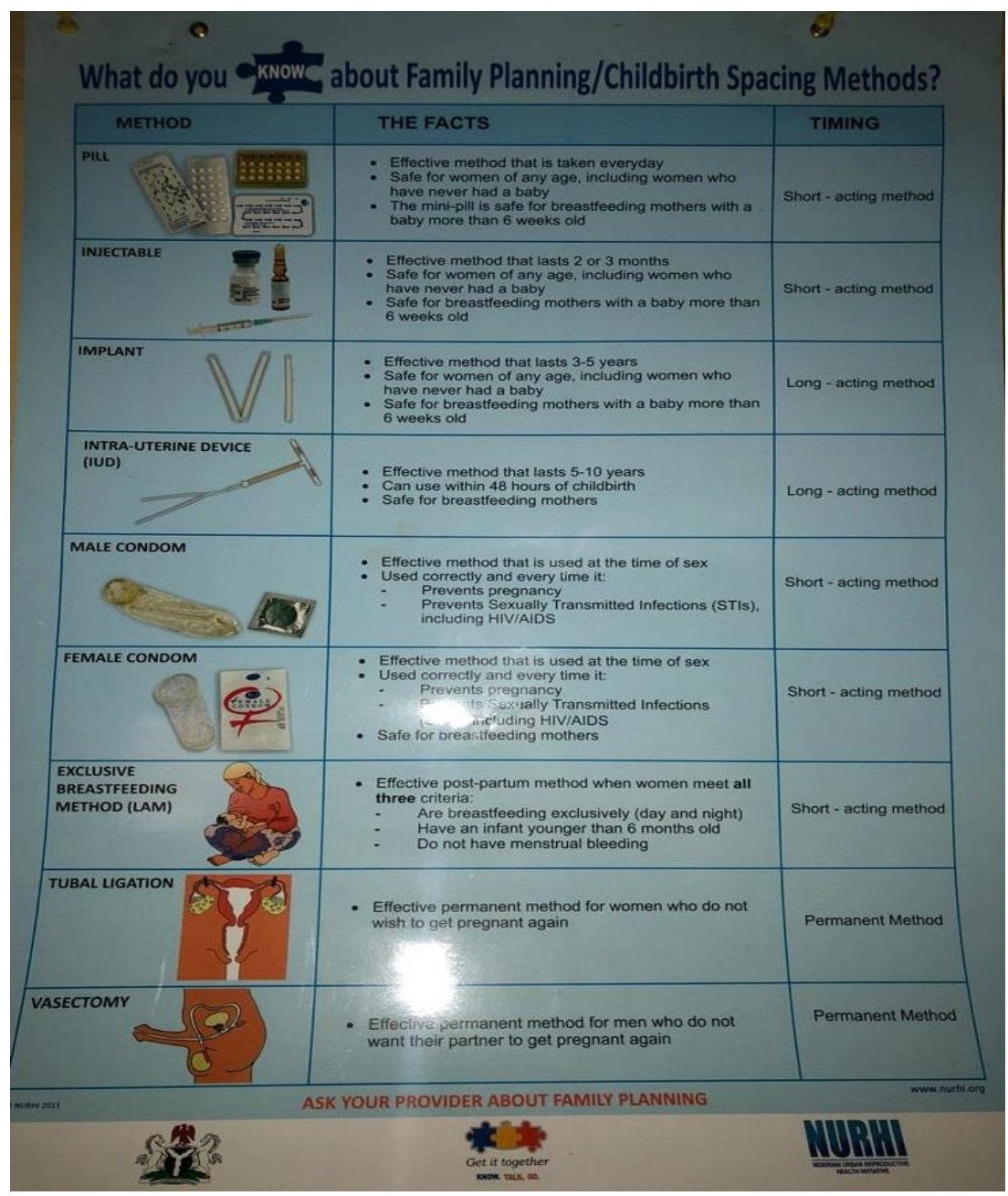

Figure 1. Modern family planning/childbirth spacing method (MFP/CSM) poster 


\section{Appendix II}

\section{QUESTIONNAIRE}

Dear Respondent,

We are carrying out a study on the "Awareness, Knowledge and Comprehension of Media Messages on Family Planning as Predictors of Practice among Civil Servants." We hereby solicit your support by completing the questionnaire objectively. Note that your responses will be treated as confidential and used for research purpose only.

Thank you.

Researchers

\section{SECTION ONE (Demography)}

Instruction: Please tick or fill in the correct information as appropriate.

1. Age: $<19$ [ ] 20-24[ ] 25-29[ ] 30-34[ ] 35-39[ ] 40-44[ ] 45-49[ ] 50> [ ]

2. Sex: Male [ ]Female [ ]

3. Marital Status: Single [ ] Married [ ] Divorced [ ] Widowed [ ]

4. Educational Background: None [ ] Primary [ ] Secondary [ ] Higher [ ]

5. Religion: Christian [ ] Muslim [ ] Other [ ]

6. Ministerial Office: Ministry of Education [ ] Ministry of Information and Strategy [ ] Ministry of Transportation [ ] Mushin General Office [ ] Alimosho General Hospital [ ] Education District II [ ] Harvey Road Health Centre [ ] Judiciary [ ] Valuation Office [ ] Lagos State Technical and Vocation Education Board [ ] Office of Auditor General [ ］Ｏshodi Medical Stores [ ]

SECTION TWO: Awareness of media messages on family planning by civil servants

Instruction: Please tick appropriately for each question where Very High Extent (VHE=5), High Extent (HE=4), Low Extent (LE=3), Very Low Extent (VLE=2), and Undecided/Neutral (U/N=1).

\begin{tabular}{|l|l|l|l|l|l|l|}
\hline S/N & ITEM & VHE & HE & LE & VLE & U/N \\
\hline 1. & I have heard of family planning messages. & & & & & \\
\hline 2. & I am aware of television messages on family planning. & & & & & \\
\hline 3. & I have seen posters of family planning messages. & & & & & \\
\hline 4. & I am aware of television series called Newman Street. & & & & & \\
\hline
\end{tabular}

5. What are the medium through which you come across family planning messages? (Please, select all that apply.)
a) Radio programmes [ ]
b) Television programmes [ ]
c) Posters[ ]
d) Organized talks [
]e) Newspaper articles [
] f) Flyers[
]g) Booklets[ ]

h) Friends and family [ ] i) Hospitals [ ]

6. How frequently do you come across family planning messages?
a) Regularly [
] b) Sometimes [
] c) Occasionally [
] d) Rarely[
] e) Never [ ]

\section{SECTION THREE: Family planning methods civil servants know based on media messages}

Instruction: Please tick appropriately for each question where Very High Extent (VHE=5), High Extent (HE=4), Low Extent (LE=3), Very Low Extent (VLE=2), and Undecided/Neutral ( $\mathrm{U} / \mathrm{N}=1)$. 


\begin{tabular}{|c|l|l|l|l|l|l|}
\hline S/N & ITEM & VHE & HE & LE & VLE & U/N \\
\hline 1. & $\begin{array}{l}\text { Media messages provide information about the short-acting family } \\
\text { planning methods (such as Oral contraceptives pills, Injectables, } \\
\text { Condoms and Exclusive breastfeeding method (LAM)) }\end{array}$ & & & & \\
\hline 2. & $\begin{array}{l}\text { Media messages educate on long-acting family planning methods } \\
\text { (such as using Implants and Intrauterine Contraceptive Devices } \\
\text { (IUDs or IUCDs) }\end{array}$ & & & & & \\
\hline 3. & $\begin{array}{l}\text { I know about the permanent family planning methods (such as } \\
\text { Tubal litigation and Vasectomy) through media messages. }\end{array}$ & & & & & \\
\hline 4. & I understand that family planning is meant for male and female. & & & & & \\
\hline 5. & Family planning is safe for pregnant/nursing mothers. & & & \\
\hline
\end{tabular}

\section{SECTION FOUR: Level of comprehension of family planning messages by civil servants}

Instruction: Please tick appropriately for each question where Very High Extent (VHE=5), High Extent (HE=4), Low Extent (LE=3), Very Low Extent (VLE=2), and Undecided/Neutral (U/N=1).

\begin{tabular}{|l|l|l|l|l|l|l|}
\hline S/N & ITEM & VHE & HE & LE & VLE & U/N \\
\hline 1. & I comprehend the language used in family planning media messages. & & & & & \\
\hline 2. & $\begin{array}{l}\text { I understand the different methods of family planning and how they } \\
\text { can be administered. }\end{array}$ & & & & \\
\hline 3. & I trust the messages I get about family planning. & & & & & \\
\hline 4. & I understand the content of posters on family planning messages. & & & & & \\
\hline 5. & $\begin{array}{l}\text { Family planning methods that the Newman series portray are } \\
\text { achievable. }\end{array}$ & & & & \\
\hline
\end{tabular}

\section{SECTION FIVE: Practice of family planning by civil servants}

Instruction: Please tick appropriately for each question where Very High Extent (VHE=5), High Extent (HE=4), Low Extent (LE=3), Very Low Extent (VLE=2), and Undecided/Neutral (U/N=1).

\begin{tabular}{|l|l|l|l|l|l|l|}
\hline S/N & ITEM & VHE & HE & LE & VLE & U/N \\
\hline 1. & I currently use a family planning method. & & & & & \\
\hline 2. & I am satisfied with my current family planning method. & & & & & \\
\hline 3. & $\begin{array}{l}\text { I encourage people to use family planning methods for child } \\
\text { spacing. }\end{array}$ & & & & & \\
\hline 4. & $\begin{array}{l}\text { Understanding of family planning messages and methods } \\
\text { influenced my use of family planning. }\end{array}$ & & & & \\
\hline 5. & $\begin{array}{l}\text { The source I get family planning messages from is credible, } \\
\text { therefore I use and will continue to engage in family planning }\end{array}$ & & & & \\
\hline 6. & Media messages encourage the use of family planning. & & & & & \\
\hline 7. & I go for regular checkups on family planning. & & & & & \\
\hline 8. & $\begin{array}{l}\text { Getting more understanding of family planning messages and } \\
\text { methods will encourage practice. }\end{array}$ & & & & \\
\hline
\end{tabular}

\section{Copyrights}

Copyright for this article is retained by the author(s), with first publication rights granted to the journal.

This is an open-access article distributed under the terms and conditions of the Creative Commons Attribution license (http://creativecommons.org/licenses/by/4.0/). 